\title{
Influence of stroke volume variation on fluid treatment and postoperative complications in thoracic surgery
}

This article was published in the following Dove Press journal:

Therapeutics and Clinical Risk Management

\section{Cengiz Sahutoglu \\ Erbil Turksal \\ Seden Kocabas \\ Fatma Zekiye Askar}

Department of Anesthesiology and Reanimation, Ege University School of Medicine, Izmir, Turkey
Correspondence: Cengiz Sahutoglu Anesteziyoloji ve Reanimasyon AD, Ege Universitesi Tip Fakultesi, 35I00 Bornova, Izmir, Turkey

Tel +902323902143

Fax +902323397687

Email csahutoglu@yahoo.com
Background: Fluid management in critically ill patients usually relies on increasing preload to augment cardiac output. In the present study, we aimed to evaluate whether stroke volume variation (SVV) can guide fluid therapy and reduce complications.

Patients and methods: In this retrospective study, a total of 88 patients who underwent lobectomy were divided into two groups: group $1(\mathrm{SVV}, \mathrm{n}=43)$ and group 2 (conventional or central venous pressure [CVP], $n=45$ ). Heart rate, blood pressure, oxygen saturation, SVV (only group 1), CVP (all patients), urea, creatinine, and hemoglobin levels before and after surgery, use of fluid, blood and inotropic agents, and postoperative complications were recorded retrospectively.

Results: The mean age of the study population was $56.9 \pm 14.4$ years and $75 \%$ of the patients were male. SVV was used in fluid therapy in $48.9 \%$ of the patients. The use of SVV resulted in an increased use of crystalloids and colloids with increased urine output per hour $(p<0.05)$. Of patients in the SVV group and the CVP group, $44.1 \%$ and $51.1 \%$ developed at least one complication, respectively ( $p=0.531$ ). The rate of respiratory complications including atelectasis, pneumonia, hypoxemia, and an increased production of secretions was $21 \%$ in the SVV group and $37.7 \%$ in the CVP group ( $p=0.104$ ). The rate of complications and the length of hospital stay were comparable between the groups $(p>0.05)$.

Conclusion: Our study results showed that the use of SVV increased the use of crystalloids and colloids and favorably affected urine output per hour but did not reduce complications in thoracic surgery.

Keywords: central venous pressure, fluid management, lobectomy, one-lung ventilation, stroke volume variation

\section{Introduction}

Fluid management usually relies on increasing preload to augment cardiac output in critically ill patients. However, recent studies have failed to demonstrate the anticipated effect in approximately $50 \%$ of the patients. ${ }^{1}$ This has resulted in a need for developing an accurate and reliable technique to guide the fluid management. Current preload variables such as central venous pressure (CVP) and pulmonary capillary wedge pressure are not reliable variables to manage fluid resuscitation. On the other hand, volumetric preload variables assessed with transpulmonary thermodilution may be superior in reflecting the left ventricular preload; however, these variables do not allow evaluation of the fluid responsiveness. ${ }^{2,3}$ As a less invasive hemodynamic monitoring system based on arterial pulse contour analysis, stroke volume variation (SVV) allows continuous monitorization of the fluid status, and several studies have suggested that 
CVP can be reliably replaced by SVV in the management of fluid therapy. ${ }^{4,5}$ In the present study, therefore, we aim to evaluate whether SVV can guide fluid therapy in thoracic surgery and reduce complications.

\section{Patients and methods}

\section{Patients}

The study protocol was approved by the institutional Ethics Committee (No. 16-3.1/3) and conducted in accordance with the principles of the Declaration of Helsinki. A total of 88 patients who underwent lobectomy between January 2014 and December 2015 were reviewed retrospectively. Patients undergoing surgical procedures other than lobectomy, those with severe valvular disease and arrhythmia, respiratory function test results below $50 \%$, or severe organ failure (kidney, liver, and heart failure), patients without an epidural catheter, and pediatric cases were excluded. The patients were divided into two groups including group 1 (patients who were monitored with the FloTrac Device, SVV group, n=43) and group 2 (patients who were not monitored with the FloTrac Device, conventional or CVP group, $\mathrm{n}=45$ ). In this study, conventional methods were collected under the heading CVP.

\section{Anesthesia management}

The patients received diazepam $5 \mathrm{mg}$ (Nervium $5 \mathrm{mg}$; Saba Pharmaceuticals, Istanbul, Turkey) as a premedication at 10:00 PM the night before and at 06:00 AM the morning before surgery. A peripheral venous access was installed and the patients were monitored with electrocardiography, pulse oxymetry, and invasive measurements of radial artery pressure and CVP. In the patients, an epidural catheter for postoperative pain management was inserted between the Th5/6 and Th9/10 intervertebral spaces. A bolus of $0.125 \mathrm{~mL} / \mathrm{kg}$ of $0.25 \%$ bupivacaine and $50 \mu \mathrm{g}$ fentanyl were added before surgical incision. Anesthesia was induced with lidocaine $1 \mathrm{mg} / \mathrm{kg}$, propofol 2-3 mg/kg, fentanyl $1-2 \mu \mathrm{g} / \mathrm{kg}$, and rocuronium bromide $0.6 \mathrm{mg} / \mathrm{kg}$. Anesthesia maintenance was achieved with desflurane $(0.5 \%-1 \%$ minimum alveolar concentration) added to $50 \%$ oxygen and $50 \%$ air mixture, remifentanil $(0.25-0.5 \mu \mathrm{g} / \mathrm{kg} / \mathrm{min})$, and propofol ( $1 \mathrm{mg} / \mathrm{kg} / \mathrm{h})$. After intubation with a double-lumen endotracheal tube, the patients were monitored in volume control mode with $8 \mathrm{~mL} / \mathrm{kg}$ tidal volume and a positive end-expiratory pressure (PEEP) of $4 \mathrm{cmH}_{2} \mathrm{O}$. In the lateral position, tidal volume was reduced to $4-5 \mathrm{~mL} / \mathrm{kg}$ in one-lung ventilation (OLV), and the fraction of inspired oxygen $\left(\mathrm{FiO}_{2}\right)$ and respiratory variables were set to maintain oxygen saturation above $92 \%$ and a partial arterial pressure of carbon dioxide between 35 and $45 \mathrm{mmHg}$. A recruitment maneuver (constant airway pressure of $40 \mathrm{cmH}_{2} \mathrm{O}$ to the whole lung for $10 \mathrm{~s}$ ) was performed twice by mechanic ventilator, when transitioning from OLV to two-lung ventilation and at the end of operation. All patients were extubated in the operating room. Epidural patient-controlled analgesia was programmed with $0.125 \%$ bupivacain $+2 \mu \mathrm{g} / \mathrm{mL}$ fentanyl at the concentration to administer a $2 \mathrm{~mL}$ bolus, $4 \mathrm{~mL} / \mathrm{h}$ infusion, a 20-min lockout interval, and a $4-\mathrm{h}$ limit of $30 \mathrm{~mL}$. Epidural patient-controlled analgesia was initiated after the patients were admitted to the intensive care unit.

\section{Fluid management Group I (SVV group)}

The FloTrac Device (Vigileo ${ }^{\text {TM}}$; Edwards Lifesciences, LLC, Irvine, CA, USA) was connected to the arterial line. The SVV, cardiac output, cardiac index (CI), stroke volume, and stroke volume index (SVI) were measured by the FloTrac Device. The measurements were taken into consideration when the tidal volume was $8 \mathrm{~mL} / \mathrm{kg}$ and the thorax was closed. All patients' preoperative fluid losses were calculated with the 4/2/1 rule ${ }^{6}$ and treated with $500 \mathrm{~mL}$ (half of the preoperative fluid losses) crystalloid fluid loading during the first hour (4/2/1 rule: $4 \mathrm{~mL}$ for the first $10 \mathrm{~kg}, 2 \mathrm{~mL}$ for the second $10 \mathrm{~kg}$, and $1 \mathrm{~mL}$ for every $1 \mathrm{~kg}$ above $20 \mathrm{~kg}$ ). In the case of SVV $\geq 13 \%$, a $2 \mathrm{~mL} / \mathrm{kg}$ bolus of crystalloid infused over 10 min was administered, and if SVI $\geq 10 \%$ the bolus was repeated until SVV $<13 \%$. If SVI was not increased by more than $10 \%$, the fluid loading was interrupted and the case was reevaluated after $15 \mathrm{~min}$. After the first $1,000 \mathrm{~mL}$ crystalloid treatment, colloid was added. The SVV measurements continued during open thoracic surgery, but SVV results did not guide fluid therapy alone during this period. SVV management used traditional methods.

\section{Group 2 (conventional or CVP group)}

Based on patients' weight, the 4/2/1 rule was used to calculate preoperative fluid losses. All patients were treated with $500 \mathrm{~mL}$ crystalloid fluid loading during the first hour. Maintenance fluid therapy was calculated using the same rule (average $110-125 \mathrm{~mL} / \mathrm{h}$ ) and titrated to hemodynamic measures (CVP between 5 and $10 \mathrm{mmHg}$, mean arterial blood pressure (MAP) $>65 \mathrm{mmHg}$, heart rate (HR) 60-100 bpm, and urine output $>0.5 \mathrm{~mL} / \mathrm{kg} / \mathrm{h}$ ). Ephedrine was administered to treat refractory hypotension despite adequate fluid therapy. Erythrocyte suspension was given when hemoglobin $<8 \mathrm{mg} / \mathrm{dL}$.

\section{Postoperative fluid management}

Postoperative fluid was given to all patients in both groups at $1,000 \mathrm{~mL} / \mathrm{m}^{2} / 24 \mathrm{~h}$ on the first postoperative day. Additional fluid was given to some patients to keep urine 
output $>0.5 \mathrm{~mL} / \mathrm{kg} / \mathrm{h}$. Colloidal solutions (hydroxyethyl starch, gelofusine, and albumin) were not used in the postoperative period.

\section{Primary and secondary endpoints}

HR, MAP, oxygen saturation, CVP (all patients), SVV (only group 1), urea, creatinine, and hemoglobin levels before and after surgery, the amount of fluids, blood products, and inotropic agents, and complications were recorded. The primary endpoint was the amount of intraoperative fluid administration between the SVV group and the CVP group during OLV and lobectomy. The secondary endpoint was comparisons of the postoperative complications between the SVV and CVP groups. Postoperative complications were defined as follows:

- Respiratory complications: pneumonia (infiltration on chest X-ray, temperature $>38^{\circ} \mathrm{C}$; signs of infection on sputum microbiology; purulent secretion differing from preoperative status), pleural effusion (chest X-ray), atelectasis (chest X-ray), respiratory failure (hypoxemia, pulmonary edema, acute respiratory distress syndrome, reintubation, requiring mechanic ventilation [oxygen saturation $90 \%$ on room air on the pulse oximeter, the ratio partial pressure arterial oxygen and fraction of inspired oxygen $<200$ in arteblood gas, chest X-ray findings]), air leak $>5$ days, increased secretions (defined by nasotracheal suctioning or fiberoptic bronchoscopy in patients who developed postoperative atelectasis, pneumonia, or hypoxemia), and bronchopleural fistula on chest computed tomography.

- Cardiac complications: heart failure, arrhythmias requiring treatment, myocardial infarction.

- Renal dysfunction: $0.3 \mathrm{mg} / \mathrm{dL}$ increase in creatinine levels compared to baseline values or need for renal replacement treatment or dialysis.

- Others: stroke (cerebral hemorrhage, infarct), ileus, mesenteric ischemia, gastrointestinal bleeding, sepsis, multiple organ failure, reoperation for any reason.

\section{Statistical analysis}

To evaluate the impact of SVV on fluid therapy, a study sample minimum size of 43 patients in each group was required (fluid volume used was $1,466 \pm 432 \mathrm{~mL}$ in group 1 (SVV group) and 1,083 $\pm 442 \mathrm{~mL}$ in group 2 (CVP group); $\mathrm{G}^{*}$ Power software (Heinrich-Heine-Universität, Düsseldorf, Germany), two-sided tests, type I error 0.01, and power 90\%). Statistical analysis was performed using SPSS version 21.0 software (SPSS Inc., Chicago, IL, USA). The Kolmogorov-Smirnov test was performed to analyze normality of the distributed data.
Descriptive data were expressed as mean \pm standard deviation (SD), median (range), or percentage. The chi-square and Fisher's exact tests were used to compare categorical variables between the groups, while the independent-sample $t$-test and Mann-Whitney $U$-test were used to analyze quantitative variables. $p<0.05$ was considered statistically significant.

\section{Ethics approval and consent to participate}

Ethics committee approval was received for this study from the Clinical Research Ethical Committee of Ege University School of Medicine (No. 16-3.1/3; March 28, 2016). The study did not require informed consent since our study is a retrospective study and the data were obtained by screening of the patient files. No identifiable protected health information was extracted during the study.

\section{Results}

One hundred and ninety-eight patients were enrolled in the study and 88 patients completed it (Figure 1). The mean age of the study population was $56.9 \pm 14.4$ years (range 20-78 years), and $75 \%$ of the patients (66 patients) were male. Of these patients, $89.8 \%$ and $10.2 \%$ underwent lobectomy due to a lung tumor and bronchiectasis, respectively. Of these patients, $25 \%$ had more than one systemic disease, while $39.8 \%$ did not have any comorbid conditions Twenty-two patients had hypertension (12 in group 1 vs 10 in group $2, p=0.626), 12$ patients had coronary artery disease ( 3 in group 1 vs 9 in group 2, $p=0.119$ ), 10 patients had diabetes mellitus (4 in group 1 vs 6 in group 2, $p=0.739$ ), 18 patients had chronic obstructive pulmonary disease (6 in group 1 vs 12 in group $2, p=0.188$ ), three patients had cerebrovascular disease ( 1 in group 1 vs 2 in group $2, p>0.999$ ), 10 patients had multinodular goitre ( 5 in group 1 vs 5 in group 2, $p>0.999$ ), and 64 patients were smokers.

Demographic characteristics of the patients are presented in Table 1. End of surgery CVP was higher in group 2 (CVP group) than group 1 (SVV group) ( $p=0.022)$. All patients' end of surgery CVP levels were higher than their baseline CVP levels (9.22 $\pm 3.6 \mathrm{mmHg}$ vs $8 \pm 2.6 \mathrm{mmHg}, p=0.003$ ) (Tables 2 and 3). In addition, SVV was used in fluid therapy for $48.9 \%$ of the patients. In the SVV group, $62.8 \%$ of patients (27 patients) responded to fluid therapy (fluid responsiveness was defined as an increase in SVI $\geq 10 \%$ after fluid challenge). The mean SVV value in the SVV group was $10.5 \% \pm 3.5 \%(4-18)$ at baseline and $12.2 \% \pm 5.3 \%(2-22)$ after surgery ( $p=0.094)$. Only $25.6 \%$ of the patients had baseline $\mathrm{SVV} \geq 13 \%$. The decrease in SVV during the OLV period was not significant when compared with baseline values. 


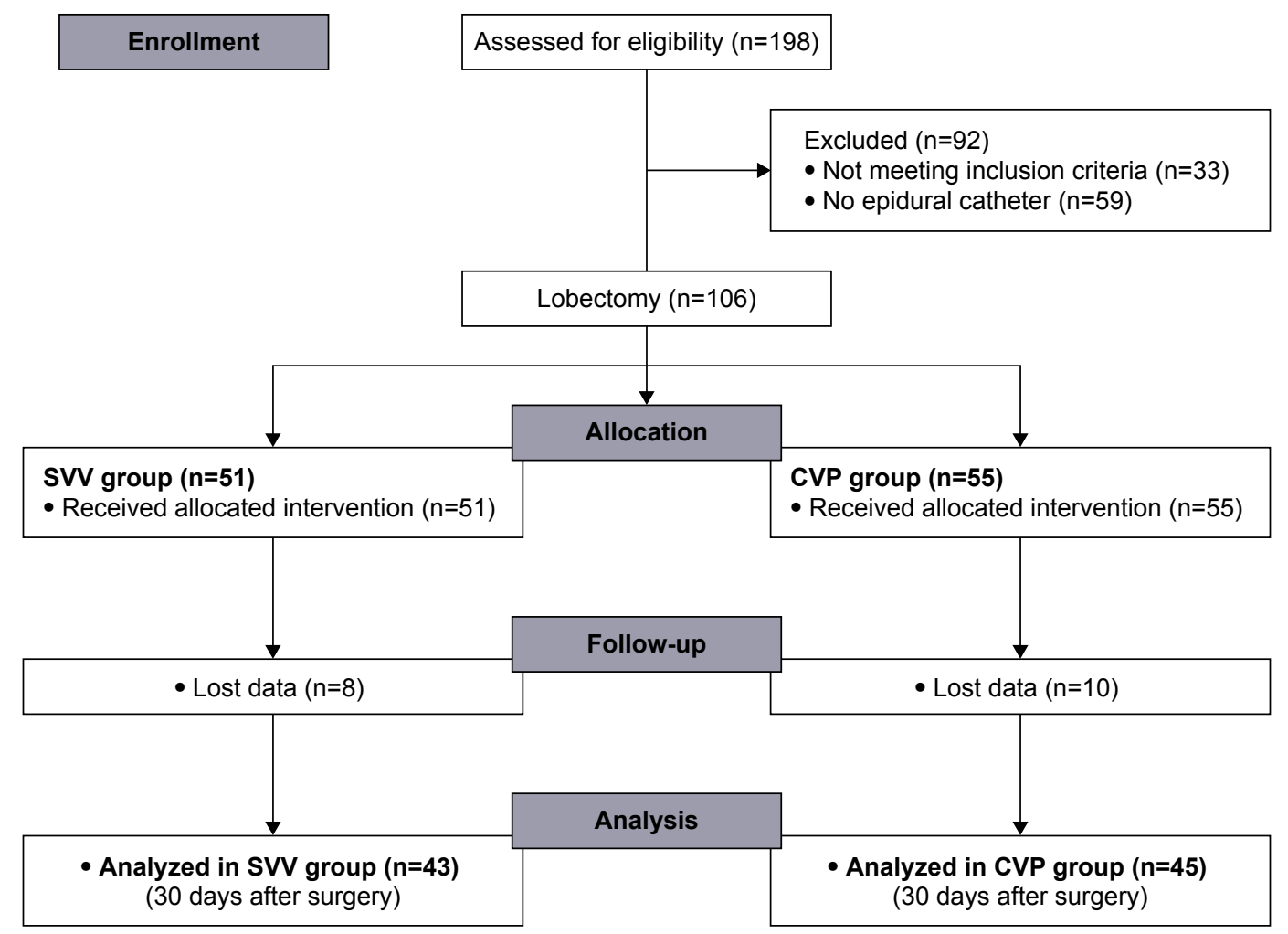

Figure I CONSORT 2010 flow diagram.

Abbreviations: CVP, central venous pressure; SVV, stroke volume variation.

However, the mean SVV values during closed thoracic surgical periods were higher than values during OLV periods ( $p=0.001)$ (Table 4).

The use of SVV resulted in an increased use of crystalloids and colloids with increased urine output per hour $(p<0.05)$. On the other hand, no significant difference in

Table I Demographic characteristics of patients

\begin{tabular}{lllll}
\hline Characteristic & $\begin{array}{l}\text { All } \\
\text { patients } \\
(\mathbf{n}=\mathbf{8 8})\end{array}$ & $\begin{array}{l}\text { SVV } \\
\text { group } \\
(\mathbf{n}=\mathbf{4 3})\end{array}$ & $\begin{array}{l}\text { CVP } \\
\text { group } \\
(\mathbf{n}=\mathbf{4 5})\end{array}$ & p-value \\
\hline Age (years) & $6 I(20-78)$ & $6 I(20-78)$ & $6 I(20-73)$ & 0.864 \\
Gender (F/M) & $22 / 66$ & $8 / 35$ & $14 / 31$ & 0.221 \\
BMI $\left(\mathrm{kg} / \mathrm{m}^{2}\right)$ & $25.9 \pm 4$ & $25.6 \pm 3.9$ & $26.1 \pm 4.1$ & 0.555 \\
BSA $\left(\mathrm{m}^{2}\right)$ & $1.8 \pm 0.2$ & $1.8 \pm 0.2$ & $1.8 \pm 0.2$ & 0.992 \\
Smoking (no/yes) & $24 / 64$ & $9 / 34$ & $15 / 30$ & 0.235 \\
Comorbidities (no/yes) & $35 / 53$ & $19 / 24$ & $16 / 29$ & 0.538 \\
FEV $(\%)$ & $87.7 \pm 17.6$ & $88.7 \pm 17.4$ & $86.8 \pm 18$ & 0.615 \\
FVC (\%) & $96.5 \pm 16.6$ & $96.1 \pm 16$ & $96.8 \pm 17.4$ & 0.860 \\
FEV,/FVC (\%) & $74.2 \pm 9.7$ & $75.2 \pm 9.3$ & $73.1 \pm 10.1$ & 0.308 \\
Side of operation & $54 / 34$ & $24 / 19$ & $30 / 15$ & 0.382 \\
(right/left) & & & & \\
\hline
\end{tabular}

Note: Data are expressed as mean \pm standard deviation, median (minimummaximum), or number of cases.

Abbreviations: BMI, body mass index; BSA, body surface area; CVP, central venous pressure; $F$, female; FEV , forced expiratory volume in I sec; FVC, forced vital capacity; M, male; SVV, stroke volume variation. the length of hospital stay and the rate of complications was observed between the groups ( $p>0.05$ ) (Tables 5 and 6).

Furthermore, at least one complication occurred in $41.8 \%$ of the SVV group and $51.1 \%$ of the CVP group ( $p=0.402$ ). The rate of respiratory complications including atelectasis, pneumonia, hypoxemia, air leak $>5$ days, and an increased production of secretions was $21 \%(\mathrm{n}=9)$ in the SVV group and $37.7 \%(\mathrm{n}=17)$ in the CVP group $(p=0.104)$. Of the patients, $13.6 \%$ had an increased production of secretions, $15.9 \%$ developed atelectasis, $8 \%$ developed pneumonia,

Table 2 Intraoperative baseline values of patients

\begin{tabular}{lllll}
\hline Characteristic & $\begin{array}{l}\text { All } \\
\text { patients } \\
(\mathbf{n = 8 8})\end{array}$ & $\begin{array}{l}\text { SVV } \\
\text { group } \\
(\mathbf{n}=\mathbf{4 3})\end{array}$ & $\begin{array}{l}\text { CVP } \\
\text { group } \\
(\mathbf{n = 4 5 )}\end{array}$ & p-value \\
\hline MAP $(\mathrm{mmHg})$ & $85 \pm 13$ & $82 \pm 13$ & $87 \pm 13$ & 0.075 \\
Heart beat $(\mathrm{bPm})$ & $90 \pm 16$ & $88 \pm 16$ & $92 \pm 16$ & 0.252 \\
CVP $(\mathrm{mmHg})$ & $8 \pm 2.6$ & $7.5 \pm 2.8$ & $8.5 \pm 2.2$ & 0.060 \\
Oxygen saturation $(\%)$ & $98.5 \pm 0.9$ & $98.7 \pm 0.8$ & $98.4 \pm 1$ & 0.075 \\
Lactate $(\mathrm{mmol} / \mathrm{L})$ & $1.2 \pm 0.5$ & $1.1 \pm 0.5$ & $1.2 \pm 0.5$ & 0.286 \\
Hemoglobin $(\mathrm{g} / \mathrm{dL})$ & $13.4 \pm 1.3$ & $13.2 \pm 1.1$ & $13.6 \pm 1.5$ & 0.178 \\
Urea $(\mathrm{mg} / \mathrm{dL})$ & $33 \pm 10$ & $33 \pm 10$ & $34 \pm 10$ & 0.527 \\
Creatinine $(\mathrm{mg} / \mathrm{dL})$ & $0.84 \pm 0.19$ & $0.85 \pm 0.2$ & $0.83 \pm 0.18$ & 0.737 \\
\hline
\end{tabular}

Note: Data are expressed as mean \pm standard deviation.

Abbreviations: CVP, central venous pressure; MAP, mean arterial pressure; SVV, stroke volume variation. 
Table 3 Postoperative values of patients

\begin{tabular}{|c|c|c|c|c|}
\hline Characteristic & $\begin{array}{l}\text { All } \\
\text { patients } \\
(n=88)\end{array}$ & $\begin{array}{l}\text { SVV } \\
\text { group } \\
(n=43) \\
\end{array}$ & $\begin{array}{l}\text { CVP } \\
\text { group } \\
(n=45)\end{array}$ & $p$-value \\
\hline MAP $(\mathrm{mmHg})$ & $84 \pm 16$ & $87 \pm 17$ & $8 I \pm 14$ & 0.059 \\
\hline Heart rate (bpm) & $75 \pm 15$ & $75 \pm 16$ & $75 \pm 13$ & 0.851 \\
\hline CVP $(\mathrm{mmHg})$ & $9.2 \pm 3.6$ & $8.3 \pm 4.1$ & $10.1 \pm 2.9$ & 0.022 \\
\hline Oxygen saturation (\%) & $98.4 \pm 1.2$ & $98.7 \pm 1.1$ & $98.1 \pm 1.2$ & 0.075 \\
\hline Lactate (mmol/L) & $|.59 \pm 0.7|$ & $1.53 \pm 0.64$ & $1.62 \pm 0.74$ & $0.6 \mathrm{II}$ \\
\hline Hemoglobin (g/dL) & $\mid \mathrm{I} .4 \pm \mathrm{I} .4$ & $11.5 \pm 1.2$ & $11.3 \pm 1.6$ & 0.409 \\
\hline Urea (mg/dL) & $38.5 \pm 14$ & $40 \pm 16$ & $37 \pm 12$ & 0.450 \\
\hline Creatinine (mg/dL) & $0.85 \pm 0.3$ & $0.87 \pm 0.3$ & $0.83 \pm 0.3$ & 0.579 \\
\hline
\end{tabular}

Notes: Data are expressed as mean \pm standard deviation. Bold data are significant at $p<0.05$.

Abbreviations: CVP, central venous pressure; MAP, mean arterial pressure; SVV, stroke volume variation.

9.1\% developed air leak $>5$ days, and 5.7\% developed hypoxemia. No patient needed either tracheal intubation or mechanical ventilation. Of all patients, 5.7\% developed cardiac complications and $3.4 \%$ developed acute renal failure (did not require dialysis) (Table 6).

\section{Discussion}

Lung surgeries (ie, lobectomy and pneumonectomy) are performed under OLV. Following these operations, noncardiogenic pulmonary edema, which is radiologically characterized by diffuse interstitial edema histologically and resembles acute respiratory distress syndrome, may develop in the remaining lung on the second or third postoperative day, despite normal pulmonary wedge pressures, and these complications are associated with high mortality rates. ${ }^{7}$ To prevent these complications, diuretics must be administered intraoperatively and postoperatively, sufficient oxygenation must be maintained, and fluid restriction must be performed. Although the use of CVP is common to evaluate the fluid status in a classical manner, semi-invasive output methods such as SVV, pulse pressure variation, Pleth
Variability Index, and echocardiography have become available with the advancement in technology. Several studies have shown that SVV has successfully predicted the fluid responsiveness, compared to the cardiac index (CI), CVP, and MAP. ${ }^{4,5}$ Tidal volume, PEEP, and compliance of the thorax and lungs are the main factors affecting SVV, and an increased cardiac preload and reduced SVV occur following thoracotomy. Therefore, it has been suggested that SVV measurements should be performed during mechanical ventilation with a tidal volume of $8 \mathrm{~mL} / \mathrm{kg}$. When switching to OLV, SVV measurements may give false results due to fact that it is unlikely to expose one lung to a high tidal volume.$^{8-10}$ In the present study, fluid therapy was guided by SVV measurements in $48.9 \%$ of the patients. The initial variables of the mechanical ventilator were set to a tidal volume of $8 \mathrm{~mL} / \mathrm{kg}$ and a PEEP of $4 \mathrm{cmH}_{2} \mathrm{O}$, and SVV was maintained below 13\%. Classically, anesthesia was performed to maintain the MAP $>65 \mathrm{mmHg}$, HR between 60 and $100 \mathrm{bpm}, \mathrm{CVP}$ between 5 and $10 \mathrm{mmHg}$, and urine output $>0.5 \mathrm{~mL} / \mathrm{kg}$. The patients received colloid (gelofusine) replacement, if the target values were not met with $1,000 \mathrm{~mL}$ of crystalloid solution. SVV values were decreased during the OLV period following thoracotomy and were increased when thorax was closed.

In their study, Fu et $\mathrm{al}^{11}$ showed that the use of SVV failed in measuring the fluid responsiveness following thoracotomy in patients undergoing pulmonary lobectomy under OLV. Also, the authors reported no significant relationship between baseline SVV and baseline CVP values, as well as between MAP, stroke volume index, CI values, and CI changes after fluid loading. In another study, Mayer et al ${ }^{12}$ demonstrated that the use of CI using the Vigileo ${ }^{\mathrm{TM}}$ FloTrac Device for target-driven fluid therapy in patients undergoing abdominal surgery reduced postoperative complications and the length of hospital stay. The length of hospital stay was 15 days versus 19 days and the rate of complications was

Table 4 Hemodynamic parameters of the SVV group

\begin{tabular}{llllll}
\hline $\begin{array}{l}\text { Measurement } \\
\text { time }\end{array}$ & MAP $(\mathbf{m m H g})$ & CVP $(\mathbf{m m H g})$ & $\mathbf{S V V}(\%)$ & SVI $\left(\mathbf{m L} / \mathbf{m}^{2}\right)$ & $\mathbf{C l}\left(\mathbf{L} / \mathbf{m i n} / \mathbf{m}^{2}\right)$ \\
\hline Baseline & $82 \pm 13$ & $7.2 \pm 3.3$ & $10.5 \pm 3.5$ & $37.8 \pm 10.6$ & $3.3 \pm 0.8$ \\
After volume loading & $82 \pm 16$ & $8.3 \pm 3.7^{* *}$ & $10.4 \pm 4.5$ & $37.4 \pm 9.7$ & $3.1 \pm 0.9$ \\
OLV I5 min & $75 \pm 10^{*}$ & $9.3 \pm 3.7^{* *}$ & $9.5 \pm 3.8$ & $40 \pm 9.6^{+}$ & $3 \pm 0.8^{\#}$ \\
OLV 60 min & $75 \pm 13^{*}$ & $9.2 \pm 3.8^{* *}$ & $8.9 \pm 3.8$ & $39.5 \pm 10.6^{+}$ & $2.7 \pm 0.6^{\#}$ \\
Closed thorax & $86 \pm 16$ & $8.7 \pm 4.4^{* *}$ & $12.2 \pm 5.3^{* * *}$ & $43.4 \pm 11.8^{+}$ & $3.1 \pm 0.8$ \\
\hline
\end{tabular}

Notes: Data are expressed as mean \pm standard deviation. *MAP values in OLV are lower than in other periods $(p<0.05)$. **CVP values were significantly higher after fluid loading $(p<0.05)$. ${ }^{* * *}$ SVV was elevated when the thorax was closed $(p=0.00 \mathrm{I}) .{ }^{+} \mathrm{SVI}$ was increased in OLV $(p=0.0 \mathrm{I} 2)$ and closed thorax $(p=0.035) .{ }^{*} \mathrm{Cl}$ was decreased in OLV $15 \mathrm{~min}(p=0.02 \mathrm{I})$ and OLV $60 \mathrm{~min}(p<0.00 \mathrm{I})$ compared to basal values.

Abbreviations: $\mathrm{Cl}$, cardiac index; CVP, central venous pressure; MAP, mean arterial pressure; OLV, one-lung ventilation; SVI, stroke volume index; SVV, stroke volume variation. 
Table 5 Intraoperative values of patients

\begin{tabular}{|c|c|c|c|c|}
\hline Characteristic & All patients & SVV group & CVP group & $p$-value \\
\hline Time to extubation (min) & II (4-25) & $15(5-25)$ & $10(4-25)$ & 0.556 \\
\hline One-lung ventilation time (min) & $139 \pm 64$ & $151 \pm 72$ & $128 \pm 55$ & 0.100 \\
\hline Operation time (min) & $242 \pm 67$ & $254 \pm 66$ & $231 \pm 67$ & 0.109 \\
\hline Length of hospital stay (days) & $6(3-22)$ & $6(3-12)$ & $6(3-22)$ & 0.161 \\
\hline Crystalloid (mL) & $\mathrm{I}, 200(300-2,300)$ & $\mathrm{I}, 500(350-2,300)$ & $1,000(300-2,000)$ & $<0.00$ I \\
\hline Colloid (mL) & $100(0-1,000)$ & $150(0-1,000)$ & $50(0-500)$ & 0.005 \\
\hline Urine $(\mathrm{mL} / \mathrm{kg} / \mathrm{h})$ & $0.65(0.2-3)$ & $0.76(0.2-3)$ & $0.6(0.2-1.3)$ & 0.009 \\
\hline Use of inotropic agent (yes/no) & $8 / 80$ & $4 / 39$ & $4 / 41$ & 0.946 \\
\hline Use of blood products (yes/no) & $8 / 80$ & $5 / 38$ & $3 / 42$ & 0.479 \\
\hline
\end{tabular}

Notes: Data are expressed as mean \pm standard deviation, median (minimum-maximum), and number of cases. Bold data are significant at $p<0.05$. Abbreviations: CVP, central venous pressure; SVV, stroke volume variation.

$20 \%$ versus $50 \%$ in the FloTrac Device group, compared to the standard group.

In a randomized controlled study conducted by Benes et al, ${ }^{13} \mathrm{SVV}$ was compared with the classical method (CVP and MAP). The use of colloids was higher in the SVV group $(1,425 \mathrm{~mL}$ vs $1,000 \mathrm{~mL})$, whereas the rate of hypotensive episodes was lower, postoperative lactate levels were lower, and the rate of complications was lower (30\% vs 58.3\%) in the SVV group. Although the length of hospital stay was shorter, the lengths of intensive care unit stay and mortality rates were similar between the two groups. Furthermore, Zhang et $\mathrm{al}^{14}$ reported that the use of SVV in target-driven fluid therapy in OLV increased the $\mathrm{PaO}_{2} / \mathrm{FiO}_{2}$ ratio, decreased the time to extubation, and decreased the rates of nausea and vomiting. The use of crystalloids and colloids and urine output per hour were significantly higher in the control group; however, there was no significant difference in the length of hospital stay between the groups.

In the present study, although the use of SVV reduced complications, the difference did not reach statistical significance. The length of hospital stay and time to extubation

Table 6 Postoperative complications

\begin{tabular}{lllll}
\hline Complications & $\begin{array}{l}\text { All } \\
\text { patients } \\
\text { (yes/no) }\end{array}$ & $\begin{array}{l}\text { SVV } \\
\text { group } \\
\text { (yes/no) }\end{array}$ & $\begin{array}{l}\text { CVP } \\
\text { group } \\
\text { (yes/no) }\end{array}$ & p-value \\
\hline All complications & $41 / 47$ & $18 / 25$ & $23 / 22$ & 0.402 \\
Respiratory complications & $26 / 62$ & $9 / 34$ & $17 / 28$ & 0.104 \\
Increased secretions & $12 / 76$ & $4 / 39$ & $8 / 37$ & 0.354 \\
Atelectasis & $14 / 74$ & $5 / 38$ & $9 / 36$ & 0.385 \\
Pneumonia & $7 / 8 I$ & $2 / 4 I$ & $5 / 40$ & 0.435 \\
Hypoxemia & $5 / 83$ & $4 / 39$ & $1 / 44$ & 0.198 \\
Air leak $>5$ days & $8 / 80$ & $3 / 40$ & $5 / 40$ & 0.714 \\
Cardiac complications & $5 / 83$ & $4 / 39$ & $1 / 44$ & 0.198 \\
Acute renal failure & $3 / 85$ & $1 / 42$ & $2 / 43$ & $>0.999$ \\
\hline
\end{tabular}

Notes: Data are expressed as number of cases. Some patients had more than one complication.

Abbreviations: CVP, central venous pressure; SVV, stroke volume variation. were similar between the two groups. The use of colloids and crystalloids and urine output were higher in the SVV group. Due to the known requirement of fluid restriction in lung resection, excessive fluid restriction was avoided in the conventional method. Fluid therapy was optimized with the use of SVV in these patients, and the differences between the operators were therefore able to be eliminated. However, $37.2 \%$ of patients did not respond to fluid therapy.

In their studies, Ashes and Slinger ${ }^{10}$ and Chau and Slinger ${ }^{15}$ suggested that positive fluid balance should not exceed $20 \mathrm{~mL} / \mathrm{kg}$ within the first $24 \mathrm{~h}$, and the use of crystalloids should be limited to $2 \mathrm{~L}$ during the operation and below $3 \mathrm{~L}$ within the first $24 \mathrm{~h}$. The use of colloids should be kept lower in adults and only be reserved to replace blood loss. In addition, urine output should be maintained above $0.5 \mathrm{~mL} / \mathrm{kg} / \mathrm{h}$ in the absence of acute renal failure and the replacement of losses to the third compartment should be avoided. Appropriate means of invasive hemodynamic monitoring systems must be used to guide the administration of vasopressor and inotropic agents and fluid resuscitation to increase tissue perfusion in the postoperative period.

Moreover, Pipanmekaporn et $\mathrm{al}^{16}$ reported an incidence of $6.7 \%$ (48 patients) for cardiovascular complications in a study of 720 patients undergoing thoracotomy for indications other than cancer. The rate of cardiovascular complications was $22.2 \%$ in patients with a positive fluid balance of $>2,000 \mathrm{~mL}$ and $7.0 \%$ in patients with a fluid balance of $\leq 2,000 \mathrm{~mL}(p=0.005)$. Cardiac arrhythmias are the most common complications, and the risk of complications was found to be 2.18-fold higher in patients with a high fluid balance $(>2,000 \mathrm{~mL})(95 \% \mathrm{CI} 1.36-3.51, p=0.001)$. The authors reported that excessive hemorrhage (48\%), hypotension without hemorrhage (29.6\%), and liberal fluid resuscitation $(22.4 \%)$ were the main causes of excessive positive fluid balance. In the present study, we attempted to maintain a 
positive fluid balance below 2,000 $\mathrm{mL}$ within the first $24 \mathrm{~h}$ in all patients, and used inotropic agents to increase tissue perfusion, when necessary. Nevertheless, the use of inotropic agents, use of blood products, and creatinine and lactate levels were similar between the two groups. Although the rate of complications was higher in the conventional methods (CVP group), despite fluid restriction, the difference did not reach statistical significance. This can be attributed to the small sample size of our study.

\section{Limitations}

Our study has some limitations. Firstly, the study is retrospective in nature and includes a small group of patients from a single institution. Secondly, SVV was not available postoperatively, because conventional parameters (MAP, HR, CVP) were used in this period. Thirdly, in the SVV group, SVV and conventional methods were used during OLV.

\section{Conclusion}

Our study results showed that the use of SVV increased the use of crystalloids and colloids, and favorably affected urine output per hour with not reduced complication rates. Therefore, we conclude that at least one method including a semi-invasive output method or echocardiography should be used to guide the fluid responsiveness in patients undergoing OLV.

\section{Acknowledgment}

This research did not receive any specific grant from funding agencies in the public, commercial, or not-for-profit sectors.

\section{Author contributions}

Conception and design: CS, ET, SK. Acquisition of data: CS, ET, SK. Analysis and interpretation of data: CS, SK, FZA. Drafting the manuscript and revising it critically: CS, ET, SK, FZA. All authors read the manuscript and have given their final approval of the version for publication.

\section{Disclosure}

The authors report no conflicts of interest in this work.

\section{References}

1. Kumar A, Anel R, Bunnell E, et al. Pulmonary artery occlusion pressure and central venous pressure fail to predict ventricular filling volume, cardiac performance, or the response to volume infusion in normal subjects. Crit Care Med. 2004;32:691-699.

2. Hofer CK, Müller SM, Furrer L, Klaghofer R, Genoni M, Zollinger A. Stroke volume and pulse pressure variation for prediction of fluid responsiveness in patients undergoing off-pump coronary artery bypass grafting. Chest. 2005;128:848-854.

3. Hofer CK, Furrer L, Matter-Ensner S, et al. Volumetric preload measurement by thermodilution: a comparison with transoesophageal echocardiography. Br J Anaesth. 2005;94:748-755.

4. Cannesson M, Musard H, Desebbe O, et al. The ability of stroke volume variations obtained with Vigileo/FloTrac system to monitor fluid responsiveness in mechanically ventilated patients. Anesth Analg. 2009;108:513-517.

5. Fu Q, Mi WD, Zhang H. Stroke volume variation and pleth variability index to predict fluid responsiveness during resection of primary retroperitoneal tumors in Hans Chinese. Biosci Trends. 2012;6:38-43.

6. Oh TH. Formulas for calculating fluid maintenance requirements. Anesthesiology. 1980;53:351.

7. Sengupta S. Post-operative pulmonary complications after thoracotomy. Indian J Anaesth. 2015;59:618-626.

8. Suehiro K, Okutani R. Influence of tidal volume for stroke volume variation to predict fluid responsiveness in patients undergoing one-lung ventilation. $J$ Anesth. 2011;25:777-780.

9. Pizov R, Cohen M, Weiss Y, Segal E, Cotev S, Perel A. Positive endexpiratory pressure-induced hemodynamic changes are reflected in the arterial pressure waveform. Crit Care Med. 1996;24:1381-1387.

10. Ashes $C$, Slinger P. Volume management and resuscitation in thoracic surgery. Current Anesthesiol Rep. 2014;4:386-396.

11. Fu Q, Zhao F, Mi W, Zhang H. Stroke volume variation fail to predict fluid responsiveness in patients undergoing pulmonary lobectomy with one-lung ventilation using thoracotomy. Biosci Trends. 2014; 8:59-63.

12. Mayer J, Boldt J, Mengistu AM, Röhm KD, Suttner S. Goal-directed intraoperative therapy based on autocalibrated arterial pressure waveform analysis reduces hospital stay in high-risk surgical patients: a randomized, controlled trial. Crit Care. 2010;14:R18.

13. Benes J, Chytra I, Altmann P, et al. Intraoperative fluid optimization using stroke volume variation in high risk surgical patients: results of prospective randomized study. Crit Care. 2010;14:R118.

14. Zhang J, Chen CQ, Lei XZ, Feng ZY, Zhu SM. Goal-directed fluid optimization based on stroke volume variation and cardiac index during one-lung ventilation in patients undergoing thoracoscopy lobectomy operations: a pilot study. Clinics (Sao Paulo). 2013;68:1065-1070.

15. Chau EH, Slinger P. Perioperative fluid management for pulmonary resection surgery and esophagectomy. Semin Cardiothorac Vasc Anesth. 2014;18:36-44.

16. Pipanmekaporn T, Punjasawadwong Y, Charuluxananan S, Lapisatepun W, Bunburaphong P, Saeteng S. Association of positive fluid balance and cardiovascular complications after thoracotomy for noncancer lesions. Risk Manag Healthc Policy. 2014;7:121-129.
Therapeutics and Clinical Risk Management

\section{Publish your work in this journal}

Therapeutics and Clinical Risk Management is an international, peerreviewed journal of clinical therapeutics and risk management, focusing on concise rapid reporting of clinical studies in all therapeutic areas, outcomes, safety, and programs for the effective, safe, and sustained use of medicines. This journal is indexed on PubMed Central, CAS,

\section{Dovepress}

EMBase, Scopus and the Elsevier Bibliographic databases. The manuscript management system is completely online and includes a very quick and fair peer-review system, which is all easy to use. Visit http://www.dovepress.com/testimonials.php to read real quotes from published authors. 